\title{
Prevalence and Sociodemographic Factors Associated with Intestinal Parasitic Infections and Schistosomiasis in the City of Barra Mansa, Rio De Janeiro, Brazil
}

\section{Maria Cristina Carvalho Espírito-Santo (D cristinasanto@usp.br)}

Centre of Excellence for PhD Studies https:// orcid.org/0000-0002-0430-5050

\section{Pedro Paulo Chieff}

Universidade de São Paulo: Universidade de Sao Paulo

Fabiana Martins de Paula

Universidade de São Paulo: Universidade de Sao Paulo

Francisco Oscar Siqueira França

Universidade de São Paulo: Universidade de Sao Paulo

Filumena Maria Silva Gomes

Universidade de São Paulo: Universidade de Sao Paulo

Vera Lúcia Pagliusi Castilho

Universidade de São Paulo: Universidade de Sao Paulo

Elenice Messias Nascimento Gonçalves

Universidade de São Paulo: Universidade de Sao Paulo

Expedito José Albuquerque Luna

Universidade de São Paulo: Universidade de Sao Paulo

Pedro Luiz Silva Pinto

Adolfo Lutz Institute: Instituto Adolfo Lutz

João Renato Rebello Pinto

Universidade de São Paulo: Universidade de Sao Paulo

Ronaldo Cesar Borges Gryschek

Universidade de São Paulo: Universidade de Sao Paulo

\section{Research Article}

Keywords: Prevalence, Sociodemographic Factors, Intestinal Parasitic Infections, Schistosomiasis

Posted Date: August 23rd, 2021

DOI: https://doi.org/10.21203/rs.3.rs-800974/v1 
License: (c) (i) This work is licensed under a Creative Commons Attribution 4.0 International License. Read Full License 


\section{Abstract}

\section{Background}

Intestinal parasitic infections (IPIs) are caused by several species of protozoa and helminths and are among the most frequent infections in many regions of the world, particularly in countries with limited access to adequate conditions of hygiene and basic sanitation, and have significant morbidity. There are few studies that assess the prevalence of intestinal parasites in Latin America. We investigated the prevalence of intestinal infections in five neighborhoods in the city of Barra Mansa / RJ / Brazil.

\section{Objective}

To evaluate the prevalence of geohelminths, protozoa and Schistossoma mansoni infection, using two parasitological methods in a population in a city in the state of Rio de Janeiro (Brazil).

\section{Methods}

Cross-sectional cohort study, conducted from September 2010 to April 2011, in individuals over five years old, to assess the prevalence of IPIs in 5 peripheral neighborhoods of Barra Mansa, a city located in the state of Rio de Janeiro (Brazil): Siderlândia, Cantagalo, São Luiz, Nova Esperança and Santa Clara, through the combination of two parasitological methods, Kato-Katz and Hoffman, having analyzed a total of six slides for each of the research participants.

\section{Results}

Results of samples from 610 individuals were collected and analyzed using the Kato-Katz (KK) and Hoffman $(\mathrm{HH})$ methods. Approximately $60 \%$ of the individuals were female, with an average age of 39.72 years. Five hundred and fifty-one (84.8\%) had access to treated water and $486(74.8 \%)$ to the sewage network. The neighborhood of Siderlândia contributed most of the casuistry $(42.9 \%)$. About $4 \%$ of participants reported a previous history of schistosomiasis. Six hundred and ten stool samples were evaluated using the Kato-Katz and Hoffmann methods. The results of parasitological examinations by the KK method showed low positivity for any diagnosed parasitosis. The HH method showed a more significant number of parasitic infections, with a higher frequency of Endolimax nana (17.4\%), followed by Blastocystis spp (10.8\%). The positivity in stool tests using the $\mathrm{KK}$ or $\mathrm{HH}$ methods was significantly higher in the Santa Clara neighborhood $(p=0.038)$, in people who use river water $(p<0.001)$ and in people who reported having had schistosomiasis previously $(p=0.021)$.

\section{Conclusions}

The use of two stool samples examined by the $\mathrm{KK}$ and $\mathrm{HH}$ methods improved the detection sensitivity and evidenced the low prevalence of IPIs in the city of Barra Mansa (RJ) / Brazil.

\section{Introduction}


Infections transmitted by protozoa and geohelminths are included in a group of neglected diseases, which can be grouped as Intestinal Parasitic Infections (IPIs) and those caused by Schistossoma spp. They are among the most widespread chronic infections in the world, despite the technical and scientific advances achieved in recent decades. Currently, IPIs still have enormous implications for child health, with important morbidity in tropical countries, particularly in low and middle income countries in Africa, Asia and Latin America, and also in the pockets of poverty of large metropolises in industrialized countries (Colley et al., 2014; Kirk et al., 2015; Jourdan et al., 2018; McManus et al., 2018; Hemphill et al., 2019; WHO, 2020).

Globally, it is estimated that 895 million people are infected with helminths transmitted by the soil [SoilTransmitted Helminths (STH): Ancylostoma duodenale, Necator americanus, Trichuris trichiura and Strongyloides stercoralis]. About 447 million by Ascaris lumbricoides, 289 million by Trichuris trichiura and 229 million are infected by hookworms (GBD et al., 2018).

In Brazil, in 2010, the prevalence of tricuriasis was estimated at 1 to $10 \%$ and that of ascariasis at 10 to $20 \%$ (Else et al., 2020).

The global prevalence of intestinal protozoa is about 184 million people infected with Giardia lamblia, 104 million with Entamoeba histolytica and 64 million with Cryptosporidium spp. (Kirk et al., 2015).

Schistosomiasis is one of the most prevalent parasitic diseases in the world, with a recent estimate of between 230 and 250 million people actively infected by this helminth, with a similar number being in a post-infection stage, but continuing to have residual morbidity (Colley et al., 2014; McManus et al., 2018).

In 2015, 844 million people did not have access to safe drinking water and 2.3 billion people did not have basic sanitation services, determining the enormous prevalence of IPIs and schistosomiasis (WHO, UNICEF, 2017). The association of IPIs with socioeconomic and environmental factors is notorious, and their direct association with the lack of access to health services and promotion, education and prevention actions for communities with precarious living conditions is classically proven (Hotez, 2009; Hotez, 2020).

Assessing the frequency of infestations by intestinal parasites is an excellent indicator not only of the socioeconomic status of the population, as well as, the life situation of vulnerable populations, living with inadequate sanitary facilities, fecal pollution of water and food, difficult accesses to information on health hygiene and contact with animals (Rollemberg et al., 2015).

School-age children are one of the high-risk groups for IPIs. Factors such as inadequate hygiene habits, the developing immune system and excessive crowding in unhealthy homes and, fundamentally, the lack of drinking water, sanitation and hygiene (WASH) contribute to the increase of these diseases in this age group (Omarova et al., 2018; Gomes et al., 2020).

IPIs have detrimental effects on the survival, appetite, growth, school attendance, cognitive performance and memory of schoolchildren (Hotez, 2009; Hotez, 2020). Prevention actions against IPIs are based on 
treatment, improvement of WASH conditions, health education and treatment of the parasitized population, and which, if fully implemented, would corroborate the sharp decline of these fully preventable diseases (Hotez, 2009; Hotez, 2020).

The benefits of mass deworming programs in regions with high IPI infestations can lessen the negative consequences on children's development, such as cognitive impairment and educational loss of the child, but if not associated with the increase in WASH measures, they will not have a definite impact in the prevalence of these infections (Pabalan, 2018; WHO, 2017; Rollemberg et al., 2015).

Studies on the prevalence of IPIs have been carried out regularly in Brazil, but no studies of this nature have been carried out previously in this region of Rio de Janeiro.

The aim of this study was to assess the prevalence of IPIs and schistosomiasis and their possible association with sociodemographic factors, in the neighborhoods of Nova Esperança, Siderlândia, Cantagalo, Santa Clara, São Luiz, Barra Mansa / RJ, by combining two parasitological methods.

\section{Material And Methods}

\section{Ethical aspects}

The Project was submitted to the Ethics and Research Committee of the Department of Infectious and Parasitic Diseases of the Faculty of Medicine of the University of São Paulo and, subsequently, to the Research Ethics Committee of the Hospital das Clínicas (CAPPesq) of the Faculty of Medicine of the University of São Paulo, São Paulo, Brazil, having been approved on May 7, 2009, under number 0405/09.

A Free and Informed Consent Form was prepared in compliance with the recommendations of Resolution No. 196 of October 10, 1996, of the National Health Council. After signing the Consent Form, a spontaneous stool sample was collected from each of the participants, and delivered to the municipality's health agents.

\section{Study design}

Study design Cross-sectional study carried out from the beginning of September 2010 to the end of April 2011, in the neighborhoods of Siderlândia, Cantagalo, São Luiz, Nova Esperança and Santa Clara. These areas have about 7,000 inhabitants, and are located nearby of the city of Barra Mansa, Rio de Janeiro, Brazil (Figs. 1 and 2). It is a predominantly urban area, and its topography is formed by hills and plains, streams, and rivers, which are sometimes sources of water for domestic use by the population of the region.

These water sources predispose the population to water-borne diseases during swimming, washing clothes and kitchen utensils, recreations, games, sand removal, among other activities.

\section{Sample study}


A study was developed in an endemic area for schistosomiasis, which has an average prevalence of $1 \%$ in the municipality of Barra Mansa, state of Rio de Janeiro, Brazil (Espírito Santo et al., 2015).

The historical series of data taken from SINAN-2009, from 2001 to 2009, revealed that the most prevalent neighborhoods are those of Siderlândia, Santa Clara, São Luiz and Nova Esperança, which belong to the Barra Mansa River basin, one of the tributaries of the Paraíba do Sul River. A process for registering individuals was developed in these neighborhoods, based on an operational schedule built with the local health team, and respecting the ethical, cultural and social parameters of the community involved.

For data collection, a questionnaire was elaborated, based on the clinical form used for the Primary Care Information System of the Family Health Program of the municipality under study, with data related to the health of the family involved, and specific data from diseases studied.

\section{Sample sizing}

Estimates regarding the frequency and distribution of enteroparasitosis and S. mansoni infection were calculated based on data from SIAB-2001/2009 (Information System of Primary Care), SINAN-2001/2009 (Information System of Diseases of Notification), of the records of the Basic Health Units and of the Population Census 2000 (Coordination of Epidemiology / SMS Barra Mansa, 2009), in addition to the records of compulsory notification of infections by S. mansoni, of the Schistosomiasis Control Program of the Municipality of Barra Mansa/RJ, period 2001/2009.

This is a systematic probabilistic sampling, involving the drawing of individuals who accepted to participate in the study, aged over five years, who had not been treated for $S$. mansoni in the last year.

The sample size was defined assuming an expected prevalence of $1 \%$ for schistosomiasis, with a margin of error of $20 \%$ and a confidence level of $80 \%$.

Thus, a sample of 561 individuals was calculated. The sample was selected at random, with systematic selection of households and random selection of the individual to be included in the sample in each household.

\section{Study of Samples}

The individuals were evaluated relating (to) infection by S. mansoni, and other parasitosis, through the parasitological examination, by the morphological methods of Kato and Miura (1954) modified by Katz et al. (1972) and Hoffman et al. (1934).

The samples were identified according to the order in which they were obtained, with the randomization number and the participant's name. After each collection, the samples were sent to the Centrolab Laboratory in Volta Redonda, State of Rio, where two slides were made for the Kato-Katz method, using the Helm Test Kit, which is a product of the reagent line for diagnosing the Institute of Technology in Immunology (Biomanguinhos) of the Oswaldo Cruz Foundation (Fiocruz), based on the technology of the Kato-Katz method. These sheets were stored in rigid polypropylene sheet boxes, with a fixed lid, lined with 
cork.The remainder of each sample was kept in vials containing $10 \%$ formaldehyde solution for conservation.

Weekly, Kato-Katz slide boxes and vials containing stool samples with $10 \%$ formalin solution were transported in a thermos box to the Central Laboratory of Parasitology, Hospital das Clínicas, Faculty of Medicine, University of São Paulo, Brazil (Espírito-Santo et al., 2015).

Faecal samples with preservatives were evaluated using the spontaneous sedimentation method (Hoffman et al.,1934), to search for eggs and larvae. To search for S. mansoni eggs, the Kato-Katz method (Kato and Miura, 1954) modified by Katz et al. (1972) was used.

Two more slides were made for each of the samples preserved in $10 \%$ formaldehyde, as well as, for each method, making a total of six slides for each of the research participants. The samples were analyzed by three exclusive professionals, using a microscope (Olympus-CX41), at the Central Parasitology Laboratory of Hospital das Clínicas, Faculty of Medicine, University of São Paulo, Brazil.

At the end of the analyses, reports were issued with the respective results and forwarded to the coordinators of the schistosomiasis program in the municipality of Barra Mansa, who were responsible for delivering the reports to the participants' homes, in addition to referring patients for treatment in the Basic Units of Health in the neighborhoods involved.

A questionnaire was used to collect sociodemographic and clinical data, based on the form used by the Primary Care Information System of the Family Health Program of the municipality under study, where we added data related to the health of the family involved and specific data on the diseases studied.

\section{Statistical analysis}

Statistical analysis was performed using 'software' SPSS 15.0 and Microsoft Excel 2003. The significance levels of the tests were fixed accepting a type 1 error of $5 \%(a=0.05)$. The characteristics of the population were described using absolute frequencies, relative frequencies, and the mean and standard deviation of ages were calculated.

The proportion of positive results for each test (prevalence) of the infection was verified, according to each of the techniques employed.

Each method of measuring $S$. mansoni infection was compared and the existence of a marginal association with the use of the McNemar test was verified (Kirkwood and Sterne, 2003).

The agreement between the results of the techniques (two-by-two) was assessed using the Cohen Kappa Index and the respective 95\% confidence interval. The existence of an association between the identification of infection by S. mansoni was evaluated, according to each method, with the age group, gender, neighborhood and use of river water, using the Chi-Square Test. Fisher's exact test or the likelihood ratio test (Kirkwood and Sterne, 2003) were used when the sample was insufficient to apply the Chi-square test. 


\section{Results}

The results relate to the observation of 650 individuals who freely participated in this study. Stool samples were analyzed using the Kato-Katz $(\mathrm{KK})$ and Hoffman $(\mathrm{HH})$ methods. The characteristics of the sampled population were also analyzed.

\section{Sociodemographic characteristics of the sampled population}

The characteristics of the sampled population, residing in five peripheral neighborhoods in the municipality of Barra Mansa (RJ), are shown in Table 1.

\section{Table 1}

Sociodemographic characteristics of the studied population, individuals from the municipality of Barra Mansa (RJ), 2011 


\begin{tabular}{|c|c|c|}
\hline Feature & Frequency & $\%$ \\
\hline \multicolumn{3}{|l|}{ Gender } \\
\hline Feminine & 385 & 59.2 \\
\hline Male & 265 & 40.8 \\
\hline \multicolumn{3}{|l|}{ Age group (years) } \\
\hline 1 to 9 & 27 & 4.2 \\
\hline 10 to 19 & 144 & 22.2 \\
\hline 20 to 49 & 250 & 38.5 \\
\hline 50 or more & 229 & 35.2 \\
\hline Average age (SD) & $39.72(21.08)$ & \\
\hline \multicolumn{3}{|l|}{ Literacy } \\
\hline Yes & 624 & 96.0 \\
\hline No & 22 & 3.4 \\
\hline Uninformed & 4 & 0.6 \\
\hline \multicolumn{3}{|l|}{ Neighborhood } \\
\hline Cantagalo & 47 & 7.2 \\
\hline Nova Esperança & 187 & 28.8 \\
\hline Santa Clara & 35 & 5.4 \\
\hline São Luiz & 102 & 15.7 \\
\hline Siderlândia & 279 & 42.9 \\
\hline \multicolumn{3}{|l|}{ Water supply } \\
\hline General Network & 551 & 84.8 \\
\hline Well or Spring & 79 & 12.2 \\
\hline Others & 1 & 0.2 \\
\hline Uninformed & 19 & 2.9 \\
\hline \multicolumn{3}{|l|}{ Use of river water } \\
\hline No & 473 & 72.8 \\
\hline Washing & 15 & 2.3 \\
\hline Wash Utensils & two & 0.3 \\
\hline
\end{tabular}




\begin{tabular}{lll} 
Baths & 5 & 0.8 \\
\hline Swimming & 5 & 0.8 \\
\hline Sand Removal & 7 & 1.1 \\
\hline Uninformed & 143 & 22.0 \\
\hline Fate of feces and urine & & \\
\hline Sewerage & 486 & 74.8 \\
\hline Pit & 7 & 1.1 \\
\hline Clear sky & 117 & 18.0 \\
\hline Uninformed & 40 & 6.2 \\
\hline
\end{tabular}

Most subjects were female with a mean age of 39.72 years. The neighborhood of Siderlândia contributed with most of the casuistry (42.9\%) and about $4 \%$ of the participants report having had schistosomiasis in the past.

Of the individuals with samples taken, $27.9 \%$ had at least one IPI diagnosed by parasitological examinations ( $\mathrm{KK}$ and $\mathrm{HH})$.

The results of the parasitological examination using both methods of 610 stool samples are shown in Table 2, where the frequency of IPI diagnoses is found, considering the results of the $\mathrm{KK}$ and $\mathrm{HH}$ parasitological methods together.

Table 2

Frequency of diagnoses of Intestinal Parasitic Infections (IPIs) and Schistosomiasis considering the results of the Hoffman $(\mathrm{HH})$ and Kato-Katz $(\mathrm{KK})$ parasitological methods together 


\begin{tabular}{lll} 
Parasitosis (HH/KK Method) & Frequency & $\%$ \\
\hline Schistossoma mansoni $(H H n=5 / K K n=4)$ & 5 & 0.8 \\
\hline Endolimax nana $(H H n=106 / K K n=0)$ & 106 & 17.4 \\
\hline Entamoeba coli $(H H n=28 / K K n=0)$ & 28 & 4.6 \\
\hline Entamoeba hartmanni $(H H n=1 / K K n=0)$ & 1 & 0.2 \\
\hline Entamoebahistolytica /dispar $(H H n=5 / K K n=0)$ & 5 & 0.8 \\
\hline Blastocystis spp /hominis $(H H n=66 / K K n=0)$ & 66 & 10.8 \\
\hline Enterobius vermicularis $(K K n=5 / H H n=5)$ & 6 & 1.0 \\
\hline Giardia lamblia /intestinalis $(H H n=11 / K K n=0)$ & 11 & 1.8 \\
\hline Strongyloides stercoralis $(H H n=9 / K K n=0)$ & 9 & 1.5 \\
\hline Lumbricoides Ascaris $(H H n=2 / K K n=4)$ & 4 & 0.7 \\
\hline Trichuris trichiura $(H H n=2 / K K n=3)$ & 3 & 0.5 \\
\hline Tenia spp(HH $n=2 / K K n=1)$ & 2 & 0.3 \\
\hline lodamoeba butschlii $(H H n=1 / K K n=0)$ & 1 & 0.2
\end{tabular}

Legend: $\mathrm{HH}=$ Hoffman; KK=Kato-Katz; $\mathrm{n}=$ number of positive results in the sample performed.

\section{Discussion}

IPIs generally constitute a significant part of Neglected Tropical Diseases (NTDs) (Hotez et al., 2009).

About two billion individuals are infected by STHs, mainly in tropical and subtropical regions, affecting vulnerable and resource-poor populations in sub-Saharan Africa, the Americas and Asia (Jourdan et al., 2018; WHO, 2020).

The global prevalence of intestinal protozoa is around 350 million infected people, considering the number of carriers of Giardia lamblia, Entamoeba histolytica and Cryptosporidium spp. (Kirk et al., 2015).

In many regions of the world, co-infection with two or more parasites is still very common in areas with poor sanitation (Abruzzi and Fried, 2011). For example, studies point to the overlapping effects of STH infections with schistosomiasis (Ezeamama et al., 2008; Campbell et al., 2016; Lo et al., 2017; Pabalan et al., 2018).

In the last 20 years, evidence has been consolidated that IPIs cause several limitations to development, particularly in children, such as malnutrition, anemia and cognitive disorders that cause educational delay, often irreversible (Stephenson et al., 2000; Ezeamama et al., 2008; Bustinduy et al., 2011; Campbell et al., 2016; Pabalan et al., 2018). 
As a result of effective IPI control programs based on mass or selective chemotherapy and sanitation measures, the prevalence of these diseases has considerably decreased in the Americas and in endemic areas of Asia (Gordon et al., 2019; McManus, 2019).

In the studied sample, of the 650 patients included, $60 \%$ were female, with no predominance of age group, $96 \%$ had some degree of literacy. The study showed that $15 \%$ of the included population did not have access to drinking water and that $19.1 \%$ did not have access to treated sewage (Table 1 ).

In the current study, we used the strategy of combining of two parasitological methods, one semiquantitative and the other qualitative, Kato-Katz and Hoffman, respectively, to determine the prevalence of IPIs, during a coproscopic census carried out from September 2010 to April 2011, in five neighborhoods of Barra Mansa / RJ. To improve the sensitivity of the methods, for each stool sample, three slides were prepared for microscopic analysis of each method, making a total of six slides per stool sample. The results of parasitological tests using the KK method showed low positivity for any diagnosed parasitosis (Table 2). The HH method showed a higher number of parasitic infections, with a higher frequency by Endolimax nana (17.4\%), followed by Blastocystis spp (10.8\%) (Table 2).

The results demonstrated that the Hoffman method showed a higher positivity for $S$. mansoni, when compared to Kato-Katz, including $S$. stercoralis, 1.5\% ( $\mathrm{N}=9)$, for which the techniques for heavy eggs have low sensitivity (Faust et al., 1938) (Table 2).

Knowledge of the epidemiology and morbidity related to IPIs, associated with more sensitive diagnoses and more effective treatment strategies, are needed to strengthen the clinical detection and management of these conditions (Campbell et al., 2016; Ryan et al., 2017).

In this sense, the present work opted for the combination of two diagnostic methods, an option already described in other studies for areas of low endemicity of IPIs (Enk et al., 2008; Glinz et al., 2010; Caldeira et al., 2012; Meurs et al., 2017).

The current study confirmed the low prevalence of S.mansoni $0.8 \%(N=5)$ in the city (Table 2). In the association between risk factors and the parasitological techniques used, a statistically significant difference $(p=<0.001)$ was observed in the variable: use of river water, confirming the need for measures to universalize basic sanitation and health education.

A systematic review and meta-analysis carried out by Gomes Casavechia et al. (2018) on the prevalence of $S$. mansoni infection in Brazil, identified the main risk factors associated with this endemic: gender, age, education, family income, contact with water and the presence of intermediate host snail.

The low prevalence indicated for $A$. lumbricoides $0.7 \%(\mathrm{~N}=4)$ and T. trichiura $0.5 \%(\mathrm{~N}=3)$ and absence of hookworms (Table 2), are lower than those observed by the WHO in other regions of the world, where a higher prevalence has been documented (GBD et al., 2018; Else et al., 2020). They may represent a satisfactory fact resulting from the frequent antiparasitic therapy offered to the population from this area and in several other regions of the world, during successive coproscopic censuses and annual treatments 
carried out since the implementation of the Schistosomiasis Control Program in the municipality (Zani et al., 2004; Enk et al., 2008; Glinz et al, 2010; Caldeira et al, 2012; Meurs et al., 2017).

On the other hand, the protist, Blastocystis sp. was observed in $10.8 \%(\mathrm{~N}=66)$ of the stool samples (Table 2). These results are in agreement with several studies (Tan, 2008; El Safadi et al., 2014; Stensvold and Clark, 2016). Although Blastocystis sp. is highlighted as a possible causative agent of bowel disease, its pathogenic status remains controversial, with many outstanding issues (Moosavi et al., 2012; El Safadi et al., 2014; Stensvold and Clark, 2016).

Regarding giardiasis, positivity was observed in 11 samples (1.8\%) by the Hoffman method (Table 2). Giardiasis is a disease of oral-faecal transmission, neglected in our environment, with a high prevalence, among other reasons because only $40 \%$ of the population in Brazil has access to properly treated sewage (Coelho et al., 2017; Gomes et al., 2020). In this study, Giardia lamblia/intestinalis was detected at a frequency of $1.5 \%(n=9)$, only in the spontaneous sedimentation method. Sedimentation procedures are the recommended methods as being easier to perform and less prone to technical errors ().

According to Hiatt et al. (1995), the examination of a stool sample will allow the diagnosis of 60 to $80 \%$ of infections; examination of two stool samples will allow 80 to $90 \%$ detection and diagnosis will be $90 \%$ if three stool samples have been examined. Probably, the evaluation of six slides from each sample, in the current study, may have significantly increased the positivity of the diagnosis. Light microscopy of stool samples is sufficient for the diagnosis of these parasitosis in infections with a high parasite load.

The Kato-Katz method is not routinely used but has been evaluated by some researchers for detection of Giardia infection however it has limitations, particularly in its sensitivity (Carvalho et al., 2012; Engels et al., 1996).

Regarding waterborne amoebas, the results identified Entamoeba histolytica in $0.8 \%$ of the samples ( $\mathrm{n}=$ 5), Entamoeba coli in 2.8\% ( $\mathrm{N}=28)$ Entamoeba hartmanni in $0.2 \%(\mathrm{n}=1)$ and lodamoeba butschlii in $0.2 \%(n=1)$, but a high prevalence of Endolimax nana was observed in $17.4 \%(\mathrm{~N}=106)$ (Table 2). The species belonging to the genera Endolimax, lodamoeba and Entamoeba coli are considered nonpathogenic (Rey, 2008; Issa, 2014).

For E. nana, E. coli, Entamoeba hartmanni, lodamoeba butschlii are commensalism, but they are significant because they have the same transmission mechanism as pathogenic protozoa and can serve as an indicator of poor local sanitary conditions (Rocha et al., 2000). The results for E. vermicularis $1 \%$ (n = 6) (Table 2), suggest that this prevalence may be underestimated, due to the use of non-specific methods for these parasites.

No hookworms positivity was observed, probably because the slides were not read fresh but after storage, which compromises the sensitivity of techniques for identifying these helminths (Hoffman et al., 1934; Kato and Miura, 1954; Katz et al., 1972; Willis, 1921) and the prevalence of S. stercoralis was only $1.5 \%$ $(\mathrm{N}=9)$. 
Deworming with albendazole and ivermectin is effective in reducing the prevalence and morbidity of soiltransmitted helminthiasis in communities with high prevalence of hookworm and strongyloidiasis (Echazú, 2017; Clark and Gilman, 2020).

Multiple parasites were identified in the studied population, a fact that can be explained by the strategy employed, where the combination of quantitative and qualitative methods resulted in the analysis of a greater quantity of feces per sample and an increase in the number of slides, resulting in better microscopic identification.

IPIs still have a significant prevalence in several regions of Brazil (Chammartin et al., 2014) and affect mainly the low-income population, without access to basic sanitation, medical care, and adequate information on prophylactic measures (Andrade et al., 2010; Bencke et al., 2006; Damazio et al., 2013).

Lodo et al. (2010) in a survey with users of a Health Unit in the city of Bom Jesus dos Perdões, São Paulo, found a prevalence of $44.7 \%$ of IPIs.

Ludwig et al. (1999) observed in a study carried out with the population of Assis, São Paulo State, that there was a correlation between the conditions of basic sanitation, expressed by the number of water and sewage connections and the frequency of parasitosis. The populations, who resided in the outskirts of the city and, with lower socioeconomic status were the most parasitized.

In this way, we highlight the need for diagnostic tools and effective control options to scale up public health interventions and improve the detection and clinical management of these infections. It must be considered that other techniques, such as serological and molecular, are more sensitive for the diagnosis of IPIs, but with reduced use by health professionals, due to their high cost and the scarcity of financial resources allocated for this purpose (Bisanzio et al., 2014; Gordon et al., 2015). The cost of serological or molecular biology tools may not be financially viable for most endemic countries.

Whereas obtain a stool sample of the subjects was not an easy process, because of cultural, aesthetic and biological issues, the preparation of six blades of each stool sample can serve as a new strategy, to be established with existing tools.

In this project, all individuals diagnosed with IPIs received test results via the Barra Mansa Municipal Health Department, being referred for outpatient treatment, if necessary.

After adequate antiparasitic treatment, studies show improvements in nutritional status and cognition, but early and long-lasting intervention would be important to prevent the irreversibility of children's cognitive and growth impairment (King, 2010; Pabalan, 2018; WHO, 2018).

IPIs are generally asymptomatic and have not shown a sensitive effect to massive deparatization with anthelmintics, except for low-income communities with the presence of children with severe conditions. 
This study demonstrated the low prevalence of pathogenic IPIs in the municipality of Barra Mansa and contributed to access to adequate antiparasitic treatment.

We know that the low prevalence found may not reflect the real situation in the Brazilian population and in many other regions of the world.

Studies of enteric parasites in our country have been limited, isolated, and rare, generally reflecting the situation in small cities, requiring more comprehensive studies, and, if possible, using methods with greater sensitivity than optical microscopies, such as, for example, the use of immunological diagnostic methods such as PCR-RT (Carvalho et al., 2012; Ryan et al., 2017; Brito da Silva Alves, 2017; Faria et al., 2017; Else et al., 2020).

The reduction in the physical condition and abilities of each parasitized individual represents an obvious and avoidable loss in working days, in the capacity to learn and in the delay in physical, mental, and social development (Stephenson et al., 2000; Ezeamama et al., 2008; Bustinduy et al., 2011; Yap et al., 2012; Campbell et al., 2016; Pabalan et al., 2018).

For an effective fight against IPIs, we agree with Alum et al. (2010) who advocate that for the global and sustainable control of enteric parasites there is a need to work on several fronts, including (1) mass education on hygiene practices, (2) improvement of public and personal health conditions and (3) and where necessary large-scale deworming campaigns.

To achieve these goals, it is essential to be prioritized in all regions where the IPIs have epidemiological importance, massive investments to enable access to clean and treated sewage water, in addition to the implementation of public health systems, free, universal, and accessible with an emphasis on health promotion, education, and prevention (Gomes et al., 2020; Vlas et al., 2016).

\section{Conclusion}

This study shows that under current conditions $15 \%$ of the population studied did not have access to drinking water and about $20 \%$ did not have access to treated sewage. However, the low prevalence of IPIs was found. The use of the strategy of combining two parasitological methods (Kato-Katz and Hoffman) associated with three slides for microscopic analysis of each method, making a total of six slides per stool sample, improved the probability of finding these parasitosis. A high prevalence of commensal parasites was found, which is extremely important because it reflects the precarious local sanitary conditions and, fundamentally, the lack of drinking water, sanitation and hygiene in the region where the study was carried out. Access to functional and sustainable basic sanitation infrastructure is an essential human right, which prevents IPIs and many other health problems, improving the quality of life in several aspects.

\section{Declarations}




\section{ETHICS APPROVAL AND CONSENT TO PARTICIPATE}

The Project was submitted to the Ethics and Research Committee of the Department of Infectious and Parasitic Diseases of the Faculty of Medicine of the University of São Paulo and, subsequently, to the Research Ethics Committee of the Hospital das Clínicas (CAPPesq) of the Faculty of Medicine of the University of São Paulo, São Paulo, Brazil, having been approved on May 7, 2009, under number 0405/09.

A Free and Informed Consent Form was prepared in compliance with the recommendations of Resolution No. 196 of October 10, 1996, of the National Health Council. After signing the Consent Form, a spontaneous stool sample was collected from each of the participants and delivered to the municipality's health agents.

\section{CONSENT FOR PUBLICATION}

A Free and Informed Consent Form was prepared in compliance with the recommendations of Resolution No. 196 of October 10, 1996, of the National Health Council. After signing the Consent Form, a spontaneous stool sample was collected from each of the participants and delivered to the municipality's health agents.

\section{AVAILABILITY OF DATA AND MATERIALS}

The authors declare that all data generated or analyzed during this study are available from the corresponding author, released upon reasonable request.

\section{COMPETING INTEREST}

The authors have declared that there is no conflict of interests.

\section{FUNDING}

This study was funded by the Research Support Foundation of São Paulo State (FAPESP, No2014/04728-1), which enabled the acquisition of material and structural resources, in addition to publication support.

\section{AUTHORS' CONTRIBUTIONS}

Conceived and designed the study: MCCES, EJAL, PPC, RCBG; contributed with analyses/tools: PPC, VLPC, EMNG, MCAS, JRRP; wrote the paper: MCCES, RCBG, FMSG and FOSF. All authors have read and 


\section{ACKNOWLEDGMENTS}

We appreciate Ms. Maria Cristina Conceição de Mello (LIM-06, FMUSP) for her technical assistance concerningthe maintenance of the $S$. mansoni biological cycle.

\section{References}

1. Abruzzi, A., Fried, B., 2011. Coinfection of Schistosoma (Trematoda) with bacteria, protozoa, and helminths. Adv. Parasitol. 77, 1-85. https://doi.org/10.1016/B978-0-12-391429-3.00005-8.

2. Alum. A., Rubino, J.R., ljaz, M.K., 2010. The global war against intestinal parasites-should we use a holistic approach? Int. J. Infect. Dis. 14, e732-e738. Epub 2010/04/20. https://doi.org/10.1016/j.ijid.2009.11.

3. Andrade, E.C., Leite, I.C.G., Rodrigues, V.O., Cesca, M.G., 2010. Parasitoses intestinais: Uma revisão sobre seus aspectos sociais, epidemiológicos, clínicos e terapêuticos. Rev. APS. 13, 231-240.

4. Bencke, A., Artuso, G.L., Reis, R.S., Barbieri, N.L., Rott, M.B., 2006. Enteroparasitoses em escolares residentes na periferia de Porto Alegre, RS, Brasil. Rev. Patol. Trop. 35, 31-36. https://doi.org/10.5216/rpt.v35i1.1890.

5. Bisanzio, D., Mutuku, F., Bustinduy, A.L., Mungaim, P.L., Muchiri, E.M., King, C.H., Kitron, U., 2014. Cross-sectional Study of the Burden of Vector-borne and Soil-Transmitted Polyparasitism in Rural Communities of Coast Province, Kenya. PLoS Negl. Trop. Dis. 8, e2992. https://doi.org/10.1371/journal.pntd.000299.

6. Brito da Silva Alves, E., Conceição, M.J., Silva, V.L., Monteiro Fonseca, A.B., Leles, D., 2017. What is the future of intestinal parasitic diseases in developing countries? Acta Trop. 171, 6-7. https://doi.org/ 10.1016/j.actatropica.2017.03.013.

7. Bustinduy, A.L., Thomas, C.L., Fiutem, J.J., Parraga, I.M., Mungai, P.L., Muchiri, E.M., Mutuku, F., Kitron, U., King, C.H., 2011. Measuring fitness of Kenyan children with polyparasitic infections using the 20meter shuttle run test as a morbidity metric. PLoS Negl. Trop. Dis. 5, e1213. https://doi.org/10.1371/journal.pntd.0001213.

8. Caldeira, K., Teixeira, C.F., Silveira, M.B., Fries, L.C.C., Romanzini, J., Bittencourt, H.R., Graeff-Teixeira, C., 2012. Comparison of the Kato-Katz and Helmintex methods for the diagnosis of schistosomiasis in a low-intensity transmission focus in Bandeirantes, Paraná, southern Brazil. Mem. Inst. Oswaldo. Cruz. 107, 690-682. https://doi.org/10.1590/s0074-02762012000500019.

9. Campbell, S.J., Nery, S.V., Doi, S.A., Gray, D.J., Soares Magalhaes, R.J., McCarthy, J.S., Traub, R.J., Andrews, R.M., Clements, A.C.A., 2016. Complexities and Perplexities: A Critical Appraisal of the Evidence for Soil-Transmitted Helminth Infection-Related Morbidity. PLoS Negl. Trop. Dis. 10, e0004566. https://doi.org/10.1371/journal.pntd.0004566. 
10. Carvalho, G.L., Moreira, L.E., Pena, J.L., Marinho, C.C., Bahia, M.T., Machado-Coelho, G.L., 2012. A comparative study of the TF- Test ${ }^{\circledR}$, Kato-Katz, Hoffman-Pons-Janer, Willis and Baermann-Moraes coprologic methods for the detection of human parasitosis. Mem. Inst. Oswaldo Cruz. 107, 80-84. https://doi.org/ 10.1590/s0074-02762012000100011.

11. Chammartin, F., Scholte, R.G.C., Guimarães, L.H., Tanner, M., Utzinger, J., Vounatsou, P., 2013. Soiltransmitted helminth infection in South America: a systematic review and geostatistical metaanalysis. Lancet. Infect. Dis. 6, 507-518. https://doi.org/ 10.1016/S1473-3099(13)70071-9.

12. Chammartin, F., Guimarães, L.H., Scholte, R.G., Bavia M.E., Utzinger J, Vounatsou P., 2014. Spatiotemporal distribution of soil-transmitted helminth infections in Brazil. Parasit. Vectors 7, 440. https://doi.org/10.1186/1756-3305-7-440.

13. Clark, T.N., Gilman, R.H., 2020. Hookworm and Strongyloides Infections. in: Ryan, E.T., Hill, D.R., Solomon, T., Aronson, N.E., Endy, T.P. (Eds.) Hunter's Tropical Medicine and Emerging Infectious Diseases, tenth ed. Elsevier, Edinburgh, pp. 845-850.

14. Coelho, C.H., Durigan, M., Leal, D.A.G., Schneider, A.B., Franco, R.M.B., Singer, S.M., 2017. Giardiasis is a neglected disease in Brazil: Systematic review of 20 years of publications. PLoS Negl. Trop. Dis. 11, e0006005. https://doi.org/ 10.1371/journal.pntd.0006005.

15. Colley, D.G., Bustinduy, A.L., Secor, W.E., King, C.H., 2014. Human schistosomiasis. Lancet. 383, 2253-2264. https://doi.org/10.1016/S0140-6736(13)61949-2.

16. Damazio, S.M., Lima, M.S., Soares, A.R., Souza, M.A.A. 2013. Intestinal parasites in quilombola community of Northern State of Espírito Santo, Brazil. Rev. Inst. Med. Trop. 55, 179-183. https://doi.org/ 10.1590/S0036-46652013000300007.

17. Echazú, A., Juarez, M., Vargas, P.A., Cajal, S.P., Cimino, R.O., Heredia, V., Caropresi, S., Paredes, G., Arias, L.M., abril, M., Gold, S., Lammie, P., Krolewiecki, A.J., 2017. Albendazole and ivermectin for the control of soil-transmitted helminths in an area with a high prevalence of Strongyloides stercoralis and hookworm in northwestern Argentina: A community-based pragmatic study. PLoS Negl. Trop. Dis. 11, e0006003. https://doi.org/10.1371/journal.pntd.0006003.

18. El Safadi, D., Gaayeb, L., Meloni, D., Cian, A., Poirier, P., Wawrzyniak, I., Delbac, F., Dabboussi, F., Delhaes, L., Seck, M., Hamze, M., Riveau, G., Viscogliosi, E., 2014. Children of Senegal River Basin show the highest prevalence of Blastocystis sp. ever observed worldwide. BMC. Infect. Dis. 14, 164. https://doi.org/10.1186/1471-2334-14-164.

19. Else, K.J., Keiser, J., Holland, C.V., Grencis, R.K., Sattelle, D.B., Fujiwara, R.T., Bueno, L.L., Asaolu, S.O., Sowemimo, O.A., Cooper, P.J., 2020. Whipworm and roundworm infections. Nat. Rev. Dis. Primers. 6, 44. https://doi.org/10.1038/s41572-020-0171-3.

20. Engels, D., Nahimana, S., Gryseels, B., 1996. Comparison of the direct faecal smear and two thick smear techniques for the diagnosis of intestinal parasitic infections. Trans. R. Soc. Trop. Med. Hyg. 90, 523-525. https://doi.org/10.1016/s0035-9203(96)90304-1.

21. Enk, M.J., Lima, A.C.L., Drummond, S.C., Schall, V.T., Coelho, P.M., 2008. The effect of the number of stool samples on the prevalence, the infection intensity, and the distribution of the infection with 
Schistosoma mansoni among a population in an area of low transmission. Acta Trop. 108, 222-228. https://doi.org/ 10.1016/j.actatropica.2008.09.016.

22. Espírito-Santo, M.C., Alvarado-Mora, M.V., Pinto, P.L., Sanchez, M.C., Dias-Neto, E., Castilho, V.L., Gonçalves, E.M., Chieffi, P.P., Luna, E.J., Pinho, J.R., Carrilho, F.J., Gryschek, R.C., 2015. Comparative Study of the Accuracy of Different Techniques for the Laboratory Diagnosis of Schistosomiasis Mansoni in Areas of Low Endemicity in Barra Mansa City, Rio de Janeiro State, Brazil. Biomed. Res. Int. 2015, 135689. https://doi.org/10.1155/2015/135689.

23. Ezeamama, A.E., McGarvey, S.T., Acosta, L.P., Zierler, S., Manalo, D.L., Wu, H.W., Kurtis, J.D., Mor, V., Olveda R.M., Friedman, J.F., 2008. The synergistic effect of concomitant schistosomiasis, hookworm, and trichuris infections on children's anemia burden. PLoS Negl. Trop. Dis. 2, e245. https://doi.org/ 10.1371/journal.pntd.0000245.

24. Faria, C.P., Zanini, G.M., Dias, G.S., da Silva, S., de Freitas, M.B., Almendra, R., Santana, P., Sousa, M.D., 2017. Geospatial distribution of intestinal parasitic infections in Rio de Janeiro (Brazil) and its association with social determinants. PLoS Negl. Trop. Dis. 11, e0005445. https://doi.org/10.1371/journal.pntd.0005445.

25. Faust, E.C., D’Antoni, J.S., Odom, V., Miller, M.J., Peres, C., Sawitz, W., Thomen L.F., Tobie, J.T., Walker, $\mathrm{H} ., 1938$. A critical study of clinical laboratory technics for the diagnosis of protozoan cysts and helminth eggs in feces. I. Preliminary communication. Am. J. Trop. Med. 18, 169183. https://doi.org/10.4269/ajtmh.1938.s1-18.169.

26. GBD 2017 Disease and Injury Incidence and Prevalence Collaborators, 2018. Global, regional, and national incidence, prevalence, and years lived with disability for 354 diseases and injuries for 195 countries and territories, 1990-2017: a systematic analysis for the Global Burden of Disease Study 2017. Lancet. 392, 1789-1858. https://doi.org/ 10.1016/S0140-6736(18)32279-7.

27. Glinz, D., Silué, K.D., Knopp, S., Lohourignon, L.K., Yao, K.P., Steinmann, P., Rinaldi, L., Cringoli, G., N'Goran, E.K., Utzinger, J., 2010. Comparing Diagnostic Accuracy of Kato-Katz, Koga Agar Plate, Ether Concentration, and FLOTAC for Schistosoma mansoni and Soil-Transmitted Helminths. Plos Negl. Trop. Dis. 4, e754. https://doi.org/10.1371/journal.pntd.0000754

28. Gomes, F.M.D.S., Santo, M.C.C.D.E., Gryschek, R.C.B., Bertolozzi, M.R., França, F.O.D.S., 2020. Access to drinking water and sewage treatment in Brazil: a challenge for the control of waterborne infectious diseases. Rev. Inst. Med. Trop. Sao Paulo. 62, e71. https://doi.org/ 10.1590/S1678-9946202062071.

29. Gomes Casavechia, M.T., de Melo, G.A.N., Da Silva Fernandes, A.C.B., De Castro, K.R., Pedroso, R.B., Da Silva Santos, T., Teixeira, J.J.V., 2018. Systematic review and meta-analysis on Schistosoma mansoni infection prevalence, and associated risk factors in Brazil. Parasitology 145, 1000-1014. https://doi.org/10.1017/S0031182017002268

30. Gordon, C.A., Kurscheid, J., Williams, G.M., Clements, A.C.A., Li, Y., Zhou, X.N., Utzinger, J., McManus, D.P., Gray, D.J., 2019. Asian schistosomiasis: current status and prospects for control leading to elimination. Trop. Med. Infect. Dis. 4, E40. https://doi.org/doi:10.3390/tropicalmed4010040. 
31. Gordon, C.A., McManus, D.P., Acosta, L.P., Olveda, R.M., Williams, G.M., Ross, A.G., Gray, D.J., Gobert, G.N., 2015. Multiplex real-time PCR monitoring of intestinal helminths in humans reveals widespread polyparasitism in Northern Samar, the Philippines. Int. J. Parasitol. 45, 477-483. https://doi.org/10.1016/j.ijpara.2015.02.011.

32. Hemphill, A., Müller, N., Müller, J., 2019. Comparative Pathobiology of the Intestinal Protozoan Parasites Giardia lamblia, Entamoeba histolytica, and Cryptosporidium parvum. Pathogens. 8, 116. https://doi.org/10.3390/pathogens8030116.

33. Hiatt, R.A., Markell, E.K., Ng, E., 1995. How many stool examinations are necessary to detect pathogenic intestinal protozoa? Am. J. Trop. Med. Hyg. 53, 36-39. https://doi.org/10.4269/ajtmh.1995.53.36.

34. Hoffmann, U.A., Pons, J.A., Janer, J.L., 1934. The sedimentation concentration method in Schistossomiase mansoni, Puerto Rico. J. Public Health. 9, 283-291.

35. Hotez, P.J., Fenwick, A., Savioli, L., Molyneux, D.H., 2009. Rescuing the bottom billion through control of neglected tropical diseases. Lancet. 373, 1570-1575. https://doi.org/ 10.1016/S01406736(09)60233-6.

36. Hotez, P.J., Booker, C., 2020. STOP: Study, Treat, Observe, and Prevent Neglected Diseases of Poverty Act. PLoS Negl. Trop. Dis. 14, e0008064. https://doi.org/10.1371/journal.pntd.0008064.

37. Issa, R., 2014. Non-pathogenic protozoa. Int. J. Pharm. Pharm. Sci. 6, 30-40.

38. Jourdan, P.M., Lamberton, P.H.L., Fenwick, A., Addiss, D.G., 2018. Soil-transmitted helminth infections. Lancet. 391, 252-265. https://doi.org/10.1016/S0140-6736(17)31930-X.

39. Kato, K., Miura, M., 1954. Comparative examinations. Jap. J. Parasit. 3, 35.

40. King, C.H., 2017. The evolving schistosomiasis agenda 2007-2017-Why we are moving beyond morbidity control toward the elimination of transmission. PLoS Negl. Trop. Dis. 11, e0005517. https://doi.org/10.1371/journal.pntd.0005517.

41. King, C.H., 2010. Health metrics for helminthic infections. Adv. Parasitol. 73, 5169. https://10.1016/S0065-308X(10)73003-7.

42. Kirkwood, B.R., Sterne, J.A.C., 2003. Essential Medical Statistics, two ed. Blackwell Science Ltd, Oxford.

43. Kirk, M.D., Pires, S.M., Black, R.E., Caipo, M., Crump, J.A., Devleesschauwer, B., Döpfer, D., Fazil, A., Fischer-Walker, C.L., Hald, T., Hall, A.J., Keddy, K.H., Lake, R.J., Lanata, C.F., Torgerson, P.R., Havelaar, A.H., Angulo, F.J., 2015. World Health Organization Estimates of the global and Regional Disease Burden of 22 Foodborne Bacterial, Protozoal, and Viral Diseases, 2010: A Data Synthesis. PLoS Med. 12, e1001921. https://doi.org/10.1371/journal.pmed.1001921.

44. Li, E.Y., Gurarie, D., Lo, N.C., Zhu, X., King, C.H., 2019. Improving public health control of schistosomiasis with a modified WHO strategy: a model-based comparison study. Lancet. Glob. Health. 7, e1414-e1422. https://doi.org/10.1016/S2214-109X(19)30346-8.

45. Lo, N.C., Addiss, D.G., Hotez, P.J., King, C.H., Stothard, J.R., Evans, D.S., Colley, D.G., Lin, W., Coulibaly, J.T., Bustinduy, A.L., Raso, G., Bendavid, E., Bogoch, I.I., Fenwick, A., Savioli, L., Molyneux, D., Utzinger, 
J., Andrews, J.R., 2017. A call to strengthen the global strategy against schistosomiasis and soiltransmitted helminthiasis: the time is now. Lancet. Infect. Dis. 17, e64-9.

https://doi.org/10.1016/S1473-3099(16)30535-7.

46. Lodo, M., Oliveira, C.G.B.D., Fonseca, A.L.A., Caputto, L.Z., Packer, MLT.,Valenti, V.E., Fonseca, F.L.A, 2010. Prevalência de enteroparasitas em município do interior paulista. Rev. Bras. Crescimento. Desenvolv. Hum. 20, 769-77.

47. Ludwig, M.K., Frei, F., Alvares Filho, A., Ribeiro-Paes, J.T., 1999. Correlação entre condições de saneamento básico e parasitoses intestinais na população de Assis, Estado de São Paulo. Rev. Soc. Bras. Med. Trop. 32, 547-55. https://doi.org/10.1590/s0037-86821999000500013.

48. McManus, D.P., Dunne, D.W., Sacko, M., Utzinger, J., Vennervald, B.J., Zhou, X.N., 2018. Schistosomiasis. Nat. Rev. Dis. Primers. 4, 13. https://doi.org/ 10.1038/s41572-018-0013-8.

49. McManus, D.P., 2019. Defeating schistosomiasis. N. Engl. J. Med. 381: 2567-2568. https://doi.org/10.1056/NEJMc1917339.

50. Moosavi, A., Haghighi, A., Mojarad, E.N., Zayeri, F., Alebouyeh, M., Khazan, H., Kazemi, B., Zali, M.R., 2012. Genetic variability of Blastocystis sp. isolated from symptomatic and asymptomatic individuals in Iran. Parasitol. Res. 111, 2311-2315. https://doi.org/10.1007/s00436-012-3085-5.

51. Omarova, A., Tussupova, K., Berndtsson, R., Kalishev, M.; Sharapatova, K., 2018. Protozoan parasites in drinking water: A system approach for improved water, sanitation, and hygiene in developing countries. Int. J. Environ. Res. Public. Health. 15, 495. https://doi.org/10.3390/ijerph15030495.

52. Pabalan, N., Singian, E., Tabangay, L., Jarjanazi, H., Boivin, M.J., Ezeamama, A.E., 2018. Soiltransmitted helminth infection, loss of education and cognitive impairment in school-aged children: A systematic review and meta-analysis. PLoS Negl. Trop. Dis. 12; 0005523. https://doi.org/10.1371/journal.pntd.0005523.

53. Rey, L., 2008. Parasitologia: parasitos e doenças parasitárias do homem nos trópicos ocidentais, fourth ed. Guanabara Koogan, Rio de Janeiro.

54. Rocha. R, S., Silva, J.G., Peixoto, S.V., 2000. Avaliação da esquistossomose e de outras parasitoses intestinais em escolas do município de Bambuí-MG, Brasil. Rev. Soc. Bras. Med. Trop. 33, 431-436.

55. Rollemberg, C.V., Silva, M.M., Rollemberg, K.C., Amorim, F.R., Lessa, N.M., Santos, M.D., Souza, A.M., Melo, E.V., Almeida, R.P., Silva, A.M., Werneck, G.L., Santos, M.A., Almeida, J.A., Jesus, A.R., 2015. Predicting frequency distribution and influence of sociodemographic and behavioral risk factors of Schistosoma mansoni infection and analysis of co-infection with intestinal parasites. Geospat Health. 10, 303. https://doi.org/10.4081/gh.2015.303.

56. Ryan, U., Paparini, A., Oskam, C., 2017. New Technologies for Detection of Enteric Parasites. Trend. Parasitol. 33, 532-546. https://doi.org/10.1016/j.pt.2017.03.005.

57. Silva, A.C.L., Diniz, M.C.P., Fonseca, E. da S, Enk, M.J., Rodrigues, N.B., 2017. Avaliação do impacto das ações do Programa de Controle da Esquistossomose no controle das geo-helmintoses em São João Evangelista, Minas Gerais, Brasil, entre 1997 e 2013. Rev. Pan-Amazônica. Saúde. 8, 37-44. https://doi.org/10.5123/S2176- 62232017000200005. 
58. Smith, H.V., Mank, T.G., 2011. Diagnosis of human Giardiasis. in: Lujan, H.D., Svard, S. (Eds), Giardia a model organism. Springer-Verlag, New York, pp. 353-374.

59. Stensvold, C.R., Clark, C.G., 2016. Current status of Blastocystis: a personal view. Parasitol. Int. 65, 763-771. https://doi.org/10.1016/j.parint.2016.05.015.

60. Tan, K.S., 2008. New insights on classification, identification, and clinical relevance of Blastocystis spp. Clin. Microbiol. Rev. 21, 639-665. https://doi.org/10.1128/CMR.00022-08.

61. Vlas, S.J., Stolk, W.A., Rutte, E.A., Hontelez, J.A.C., Bakker, R., Blok, D.J., Cai, R., Houweling, T.A., Kulik, M.C., Lenk, E.J., Luyendijk, M., Matthijsse, S.M., Redekop, W.K., Wagenaar, I., Jacobson, J., Nagelkerke, N.J., Richardus, J.H., 2016. Concerted efforts to control or eliminate neglected tropical diseases: how much health will be gained? PLoS Negl. Trop. Dis. 10, e0004386. https://doi.org/ 10.1371/journal.pntd.0004386.

62. World Health Organization, 2013. World Health Assembly Resolution WHA 66.12

63. Neglected tropical diseases. World Health Organization, Geneva.

64. WHO, 2017.Guideline: preventive chemotherapy to control soil-transmitted helminth infections in atrisk population groups. World Health Organization, Geneva. (Licence: CC BY-NC-SA 3.0 IGO).

65. WHO, 2002. Expert Committee. Prevention and Control of Schistosomiasis and Soil-Transmitted Helminthiasis. Technical Report Series. WHO, Geneva.

66. WHO/UNICEF, 2017. Progress on Drinking Water, Sanitation and Hygiene: 2017 Update and SDG Baselines. WHO, UNICEF, Geneva.

67. WHO, 2018. Report of the WHO Advisory Group on deworming in girls and women of

68. reproductive age. Rockefeller Foundation Bellagio Center, Bellagio, Italy. 28- 30 June 2017 (WHO/CDS/NTD/PCT/2018.01). World Health Organization, Geneva. (Licence: CC BY-NC-SA 3.0 IGO).

69. WHO, 2020. Soil-transmitted helminth infections. Newsroom. WHO, https://www.who.int/newsroom/fact-sheets/detail/soil-transmitted-helminth-infections. (accessed july 2021).

70. Willis, H.H., 1921. A simple levitation method for the detection of hookworm ova. Med. J. Aust. 8, 375-376. .

71. Yap, P., Du, Z.W., Chen, R., Zhang, L.P., Wu, F.W., Wang, J., Wang, X.Z., Zhou, H, Zhou, X.N., Utzinger, J., Steinmann, P., 2012. Soil-transmitted helminth infections and physical fitness in school-aged Bulang children in southwest China: results from a cross-sectional survey. Parasit. Vectors. 5, 50. https://doi.org/10.1186/1756-3305-5-50.

72. Zani, L.C., Favre, T.C., Pieri, O.S., Barbosa, C.S., 2004. Impact of Antihelminthic Treatment on Infection by Ascaris Lumbricoides, Trichuris trichiura, and Hookworms in Covas, a Rural Community of Pernambuco, Brazil. Rev. Inst. Med. Trop. São Paulo. 46, 63-71. https://doi.org/10.1590/s003646652004000200002.

\section{Figures}




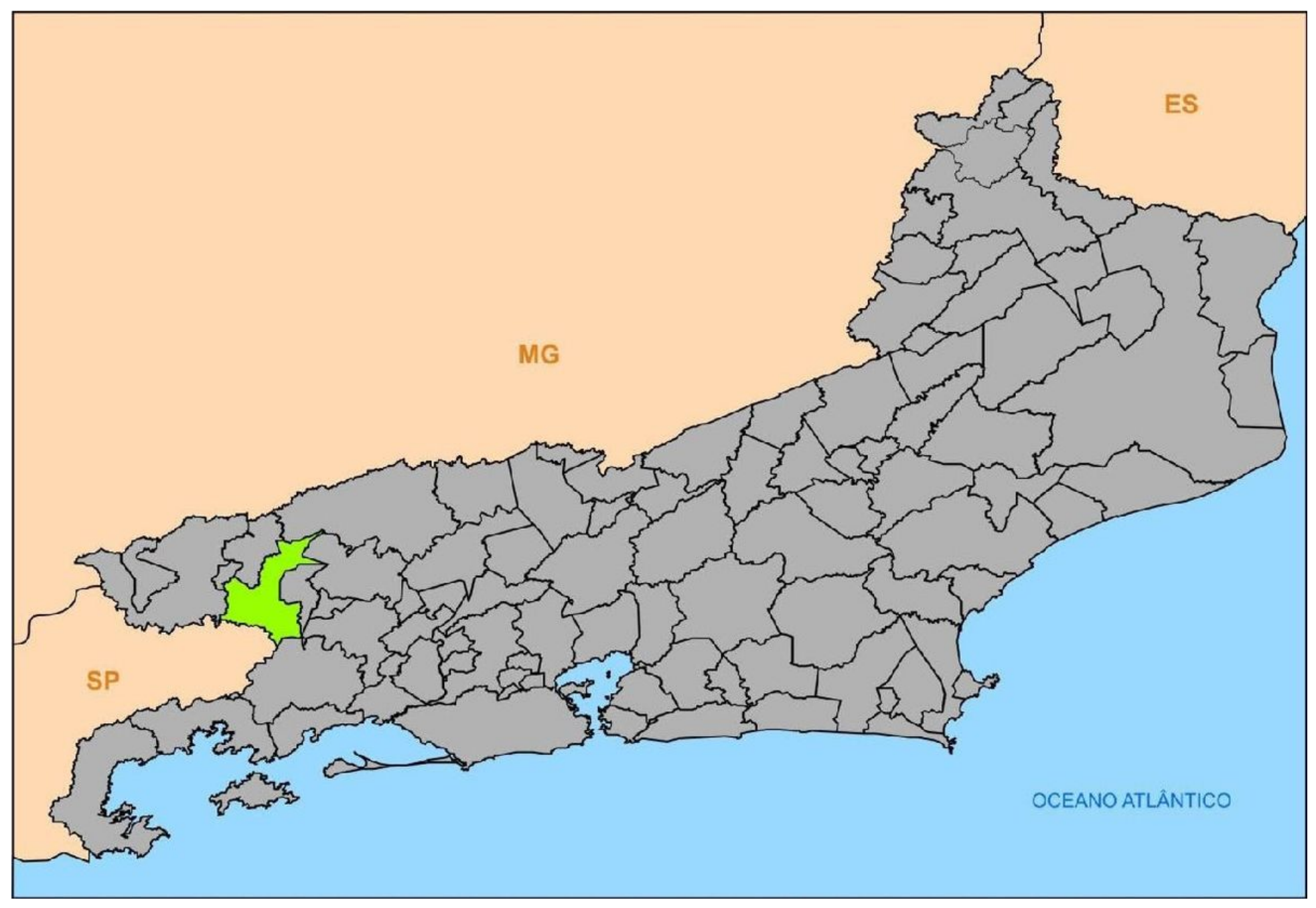

\section{Figure 1}

Map of the State of Rio de Janeiro (Grey) and the Municipality of Barra Mansa (Green). 


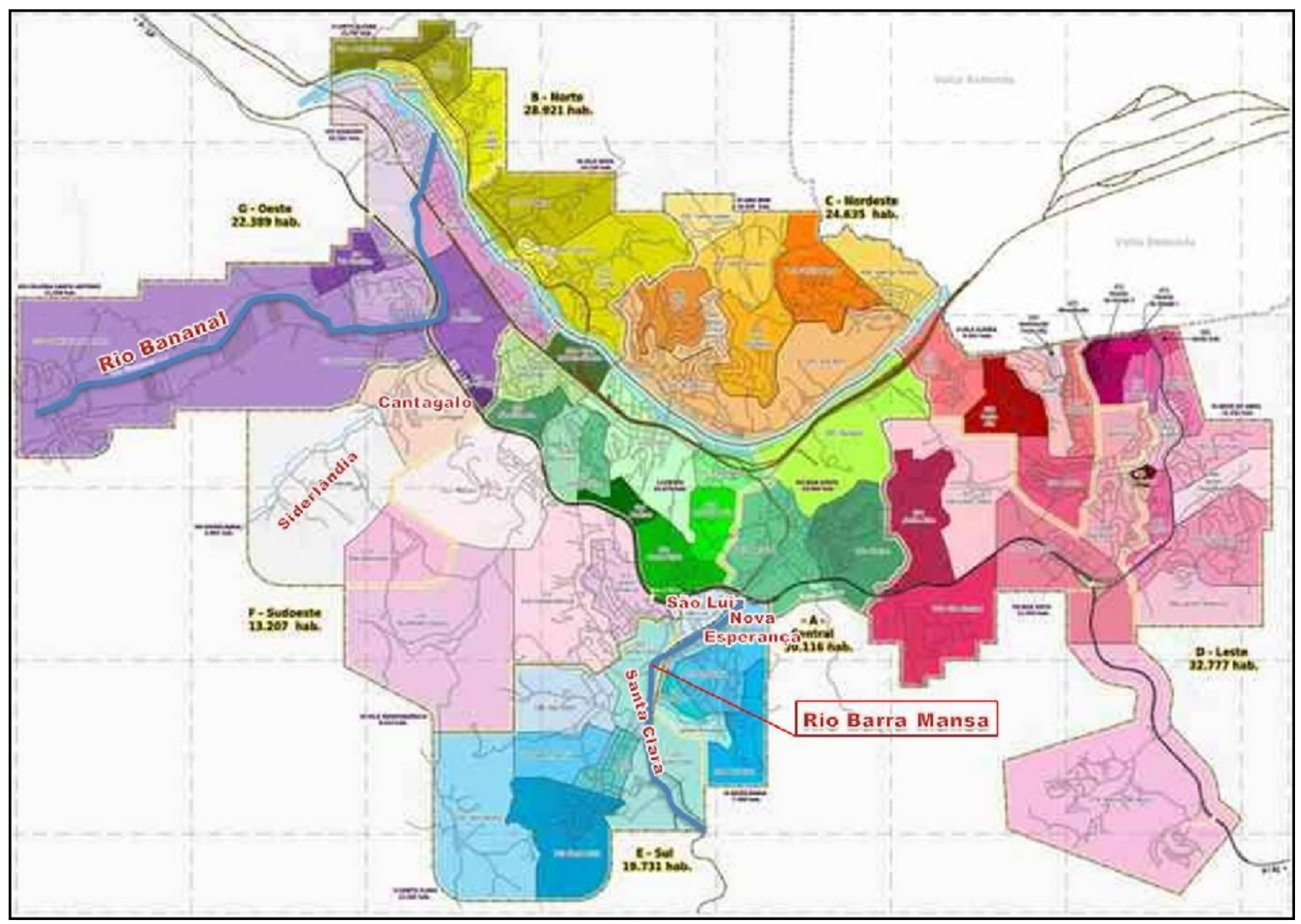

\section{Figure 2}

Map of the Municipality of Barra Mansa (RJ), highlighting the 5 neighborhoods where the study was carried out, and crossed by the Paraíba do Sul River and its tributaries, 